\title{
Risk Factors Associated With Readmissions of Hospitalized Mentally Ill Patients
}

\author{
Hanan E. Abd El Aziz Rady ${ }^{1}$, Mona T. El-Nady ${ }^{2}$ \\ Assistant prof. of Psychiatric/Mental Health Nursing, Faculty of Nursing, Cairo University
}

\begin{abstract}
Readmission is commonly used as an outcome or quality indicator for psychiatric inpatient services. This study aimed to investigate the risk factors associated with readmissions of hospitalized mentally ill patients. A descriptive correlation design was utilized in this study. A purposive sample was composed of 120 mentally ill patients. Data were collected from Al-Abbassia hospital for mental health. Tools for data collection, there were four tools included personal data interviewing sheet such as age, gender, marital status, level of education, diagnosis, number of admissions, length of stay in hospital, Medication Adherence Rating Scale, Life Events Questionnaire and Multidimensional Scale of Perceived Social Support .Results, it was found that, 45.8\% of the studied subjects were diagnosed as schizophrenic, while $13.4 \%$ were depressed, nearly two thirds of them $64.1 \%$ were admitted to the hospital from one to three times. There was statistical significant correlation between medication adherence and patients' gender. Also, statistical significant correlation was found between length of hospital stay and medication adherence. Conclusion, readmission was high among psychiatric patients. Poor adherence to medication was associated with psychiatric early readmission. Recommendations, implementation of psycho-educational program for patients and their families to reduce risk factors associated with readmission and preventive measures. Future studies should be applied to include other variables related to readmission.
\end{abstract}

Key words: Risk factors, Readmission, Hospitalized, Mentally ill patients

\subsection{Background of the Study}

\section{Introduction}

Readmission of inpatients has been one of the most important problems in the field of psychiatry for the last decades $[1,2]$."The problem has a major role in reducing the quality of life and increasing the years of lost life [3]. About one-third of patients admitted to psychiatric services will probably be readmitted within a year [4].Readmissions are costly and disruptive to individuals and families and can lead both providers and patients to feeling demoralized or having a sense of failure [5].Although readmissions can result from increased severity of psychiatric illness, ineffective inpatient care, or lack of adherence with outpatient care, in some cases it may be more related to community resource issues such as employment and residential status"[6].

Psychiatric readmission is influenced by multiple factors and it should be assessed within the framework of each health care system. Readmission has been utilized as an indicator of whether social networks will accept mentally ill patients and, more recently, as an indicator of the quality of health services. However, there is no consensus on the reliability of this parameter for measuring the quality of care [7].

Some risk factors can precipitate patients' pathways toward psychiatric hospitalization and these factors could impose heavy burdens on their caregivers and the community. Previous studies in developed countries show that financial, emotional and practical burdens [8] reduced social contact and lower social support [9].A high readmission rate can reflect a large number of patients who cannot be satisfactorily accommodated in communities and can be used as an indicator of inadequacy or inappropriateness of community-based aftercare. It increases the cost of the health care system and workload of the mental health care workers[10]. Repeat admissions may be responsible for up to $60 \%$ of hospital expenditure. Readmission is a painful experience for the patients and their families. The cost of multiple admissions to the patients and the relatives in terms of distress, morbidity and mortality is immeasurable. It has been reported that the more relapses, the poorer the prognosis and long term outcome for patients with mental disorders like schizophrenia[11].

Readmission is commonly used as an outcome or quality indicator for psychiatric inpatient services. Hospital readmission, particularly when it occurs within relatively short time after previous discharge, is often seen as a failure of the earlier hospital admission [12]. Previous studies done by [5] reported that"key factors in decreasing the likelihood of subsequent psychiatric admissions such as rendering sufficient inpatient care to address adequately the acute presenting problem and stabilize the patient's psychiatric status, ensuring an adequate discharge planand delivery of sufficient support services to transition psychiatric care successfully from an inpatient to an outpatient setting (e.g., discharge services, follow up calls, short-term case management, bridge visits, and psycho-education), and continuing adequate outpatient services to allow the individual to remain in the community" .Moreover, increased likelihood of readmission was observed to be associated with 
various factors, including predisposing factors such as prior history of psychiatric hospitalization, disease severity, alcohol and substance useand lower level of patient function at dischargeas well as aftercare-related factors such as inadequate community support and ambulatory care visits [13].However, poorly treated psychiatric patients might be vulnerable to increased risks of extended hospital stays and re-hospitalization, which may ultimately cause surplus medical expenditure. High readmission rate has been frequently considered as an indicator of adverse prognostic outcomes in psychiatric inpatients [14].Medication non adherence was reported as an important predictor of readmission also its one of the major problems faced in the treatment of psychiatric illness. However, treatment adherence remains a significant problem in the long term care of schizophrenia $[12,15]$.

Determining the factors that contribute to the readmission phenomenon may assist in the development of programs and policies to prevent readmission, improve patient care and quality of life, as well as reduce the costs of care, especially in care models with reduced availability of beds and greater restrictions for caring for mentally ill patients[16].Moreover severe mental illnesses are often characterized by a chronic relapsing course that may require repeated hospital admissions, several potential predictors of readmission has identified following a psychiatric hospitalization as poor access to past-discharge outpatient services, younger age, more severe clinical diagnosis (e.g. schizophrenia or bipolar disorder), lack of supportive significant others (being unmarried, divorced, or widowed), medication non-adherence and poor access to adequate housing [13].

\section{Significance of the Study}

Repeated psychiatric hospitalizations affecting primarily individuals with a serious mental illness are a substantial problem. Little is known about the effectiveness of different lengths of hospital stay for these patients, transition support services after discharge, short term alternatives to psychiatric re-hospitalization, or long term approaches for reducing psychiatric re-hospitalization .Early readmission is high among psychiatric patients. Poor adherence to medication is associated with psychiatric early readmission. If the treatment program seeks to decrease the incidence of early readmission, greater attention should be provided to help the patients to recognize their own symptoms and understand their illness with the aim to improve medication adherence[16]psychiatric mental health nursing and advanced practice registered nurse PMH-APRNs assess, diagnose and treat individuals and families with psychiatric disorders or the potential for such disorders using their full scope of therapeutic skills including the prescription of medication and administration of psychotherapy .PMH-APRNs often own private practices and corporation as well as consult with groups, communities and corporation [17].Therefore, healthcare providers need to recognize the factors associated with readmission rate among hospitalized mentally ill patients so they can be prevented. A better understanding of the factors related to readmissions needed to help better management and early intervention. Understanding these factors will decrease the number of readmissions and hospital costs [7]. It seems that those in-patients who are seeking re-hospitalization tend to repeat some of these treatment-seeking behaviors and may assist nurses in planning care.

The psychiatric nurse should design strategies to strengthen the linkages between the client's professional and personal social networks. This can be achieved through family group therapy, where clients' families meet together for the purpose of sharing information and gaining social support. Enhance role of outpatient psychiatric units to play crucial role in decrease hospitalization among psychiatric patients.

\subsection{Aim}

This research aimed to investigate factors associated with readmission of hospitalized mentally ill patients.

\section{I.3. Research questions}

- What are the factors associated with readmission among mentally ill patients?

- Is there a relationship between medication adherence and readmission among mentally ill patients?

- Is there a relationship between stressful life events and readmission among mentally ill patients?

- Is there a relationship between social support and readmission among mentally ill patients?

\subsection{Research Design}

\section{Subjects And Methods:}

A descriptive correlation design was utilized in this study.

\subsection{Subjects}

A purposive sample was composed of 120 mentally ill patients with different psychiatric diagnoses.

\section{Inclusion criteria}

- Both gender.

- Agree to join in the study.

-Inpatients mentally ill.

- Had previous readmission.

-Free from other organic disorders. 


\section{Exclusion criteria}

-Mentally retarded patients.

-Chronic mentally ill patients.

\subsection{Setting}

The study was conceded in Al-Abbassia hospital for mental health

2.4. Tools of data collection

Four tools were utilized by the researchers. To ensure content validity three panel of expertise in the field revised all the tools.

\section{1- Socio-demographic data sheet}

It composed of items seeking information about personal and medical data questionnaire, background for patients and their family such as age, gender, marital status, level of education, diagnosis, number of admissions,length of stay in hospital, family history,etc.,

\section{2- Medication Adherence Rating Scale (MARS)}

The Medication Adherence Rating Scale (MARS) by [18]10 items ranged between yes or no used to measure medication adherence in psychosis. Researchers Used the MARS tool to determine the patients' willingness and ability to take oral medication every day. The total score was ranged between (0-10).Reliability was tested using a measure of internal consistency Cronbach's alpha, and test-retest reliability. The reliability analysis of the MARS using Cronbach's alpha was 0.75 . High scores indicated adherence to medication while low scores indicated non adherence to medication translation and back translation was done by two researchers.

\section{3- Life Events Questionnaire (LEQ) (Brugha,1990)}

It was 12 items measured the common life events that tend to be threatening [19].The list of the 12 stressful life events included personal suffering from a serious illness, injury or assault; a close relative suffering from a serious illness, injury or assault; death of a parent, spouse/ partner, child, brother or sister; death of a close family friend or another relative; marital separation; break-up of steady relationship; serious problem with a close friend, neighbor or relative; redundancy/sacking from job; unsuccessfully seeking work for more than 1 month; major financial crisis, each item was scored 1 if it was checked and 0 if not . The test-retest reliability was reported as 0.84 for a three month period and 0.66 for a six month period. Concurrent validity ranged from a Kappa of 0.70 to 0.90 the total scoring system was ranged from(0-12). Translation and back translation was done by two researchers.

\section{4- Multidimensional Scale of Perceived Social Support (Zimet, 1988)}

The Multidimensional Scale of Perceived Social Support MSPSS is an instrument which specifically addressed the subjective assessment of social support adequacy. It was a 12-item self-rated instrument designed to assess perceptions of social support from three specific sources: family, friends and significant others. The MSPSS assessed the extent to which respondents perceived social support from each of those sources and was divided into three subscales: family (items 3,4,8,11); friends (items 6,7,9,12) and significant others (items $1,2,5,10)$. It used a 7 - point Likert type response format ranged between $(1=$ very strongly disagree, $7=$ very strongly agree). Each of the three subscales is assessed with four items. Higher score indicates better perceived social support translation and back translation was done by two researchers. Translation was done by two researchers. Reliability and validity were tested (0.84and 0.90) respectively the total scoring system was ranged from (12-84).

\subsection{Pilot Study}

It was carried out on $10 \%$ of the study subjects to test the clarity, feasibility time to fill out the questionnaire .Subjects involved in the pilot study were excluded from the study and the necessary modifications were done. Pilot study revealed that the average length of the time needed to complete the structured questionnaire schedule was approximately 30-45 minutes with each patient.

\subsection{Procedure}

An official permission was obtained from the concerned hospital authority to conduct the proposed study, the researchers contacted the patients who met the inclusion criteria from different section in the hospital, then they explained the nature and aim of the study, its importance and benefits to gain their cooperation and content of the tools to establish an initial rapport between subjects and researchers. All questions were answered and detailed explanation was given to obtain their acceptance and cooperation during the interview sessions. Data collected through interview with patients through using different tools. It was revised by three panels of experts in the psychiatric field to assure the content validity of each . The average time 
needed for completion of the interview was around 30-45 minutes. Data collection was done in a period of three months from the beginning of October to the end of December 2016. The investigators were available for 2 days/week, from 9.00 A.m. to 12, 00 P.m.

\subsection{Ethical Consideration}

An Informed consent was granted from each participant, then brief description of the purpose of the study and the type of questionnaires required to be filled was given to each participant. Anonymity and confidentiality were also assured through coding the data in addition.

\subsection{Statistical Design}

The collected data were coded and examined using SPSS version 19. The collected data were summarized and tabulated using descriptive statistics. Correlation between variables was evaluated using Pearson correlation coefficient. Significance was adopted at $p<0.05$ for interpretation of results of tests of significance.

\section{Results}

Table (1) showed that, $61.7 \%$ of the studied subjects were males, while $38.3 \%$ of them were females. In relation to subjects' age, results revealed that $25 \%$ of them their age was less than 28 years old, while $42.2 \%$ were more than 50 years old. Regarding marital status it was found that, $37.5 \%$ of the studied subjects were single and $29.2 \%$ were married. In relation to level of education nearly half of the subjects $59.2 \%$ had moderate education, $45.8 \%$ and29.2\% were illiterate. According to occupation more than half of the subjects were working.

Table (1): Frequency and percentage distribution of the studied subjects according to their demographic variables $(\mathrm{N}=120)$

\begin{tabular}{|c|c|c|}
\hline Demographic Characteristics & $\begin{array}{l}\text { Frequency } \\
\mathbf{N}\end{array}$ & $\begin{array}{r}\text { (Percentage) } \\
(\%)\end{array}$ \\
\hline \multicolumn{3}{|l|}{ Gender } \\
\hline Male & 74 & 61.7 \\
\hline Female & 46 & 38.3 \\
\hline Total & 120 & 100 \\
\hline \multicolumn{3}{|l|}{ Age } \\
\hline $18<28 y$ & 30 & 25 \\
\hline $29<39 y$ & 36 & 30 \\
\hline $40<50 y$ & 25 & 20.8 \\
\hline More than $50 \mathrm{y}$ & 29 & 24.2 \\
\hline $\begin{array}{l}\text { Total } \\
\text { Grand mean score: } 38.1 \pm 12.4\end{array}$ & 120 & 100 \\
\hline \multicolumn{3}{|l|}{ Marital status } \\
\hline Single & 45 & 37.5 \\
\hline Married & 35 & 29.2 \\
\hline Divorced & 38 & 31.7 \\
\hline Widowed & 2 & 1.7 \\
\hline Total & 120 & 100 \\
\hline \multicolumn{3}{|l|}{ Level of education } \\
\hline Illiterate & 35 & 29.2 \\
\hline Moderate & 55 & 45.8 \\
\hline High & 30 & 25 \\
\hline Total & 120 & 100 \\
\hline \multicolumn{3}{|l|}{ Occupation } \\
\hline Working & 71 & 59.2 \\
\hline Not working & 49 & 40.8 \\
\hline Total & 120 & 100 \\
\hline \multicolumn{3}{|l|}{ Residence } \\
\hline Urban & 66 & 55 \\
\hline Rural & 54 & 45 \\
\hline Total & 120 & 100 \\
\hline
\end{tabular}

Table (2) demonstrated that, $45.8 \%$ of the studied subjects were diagnosed as schizophrenic while $13.4 \%$ of them were depressed. In relation to number of hospitalization, nearly two thirds of them $64.1 \%$ were admitted to the hospital from one to three times, while $8.4 \%$ were admitted to the hospital for 4-6 times. Regarding medication adherence $35 \%$ were adhered to medication also $30 \%$ of them were sometimes adhered to medication. According to hospital stay/day, results showed that the mean score was 162.09 \pm 318.5 . 
Table (2): Frequency and percentage distribution of the studied subjects according to their medical profile $(\mathrm{N}=$ 120)

\begin{tabular}{|c|c|c|c|}
\hline Variables & & Frequency N & (Percentage) $(\%)$ \\
\hline \multicolumn{4}{|l|}{ Diagnosis } \\
\hline Schizophrenia & 55 & 45.8 & \\
\hline Manic depressive & 25 & 20.8 & \\
\hline Depression & 16 & 13.4 & \\
\hline Mania & 24 & 20 & \\
\hline Total & 120 & 100 & \\
\hline \multicolumn{4}{|l|}{ Number of hospitalization } \\
\hline $1-3$ times & 77 & 64.1 & \\
\hline $4-6$ times & 33 & 27.5 & \\
\hline More than 6 times & 10 & 8.4 & \\
\hline $\begin{array}{l}\text { Total } \\
\text { Grand mean score: } 3.7 \pm 3.0\end{array}$ & 120 & 100 & \\
\hline \multicolumn{4}{|l|}{ Medication adherence } \\
\hline Yes & 42 & 35 & \\
\hline No & 42 & 35 & \\
\hline Sometimes & 36 & 30 & \\
\hline Total & 120 & 100 & \\
\hline \multicolumn{4}{|l|}{ Health insurance } \\
\hline Yes & 37 & 30.8 & \\
\hline No & 83 & 69.2 & \\
\hline Total & 120 & 100 & \\
\hline
\end{tabular}

Table (3) illustrated that $55.8 \%$ of the studied subjects were sexually satisfied in their relationship. More than fifty percent of the studied subjects had financial problems. In relation to communication problems nearly half of them $50.8 \%$ had communication problems with their family .In relation to suicide minority of them $20.8 \%$ had history of suicide and $27.5 \%$ of them were addict

Table (3):Frequency and percentage distribution of the studied subjects according to their relationships $(\mathrm{N}=$ 120)

\begin{tabular}{|c|c|c|c|}
\hline & Variables & $\begin{array}{r}\text { Frequency } \\
\mathbf{N}\end{array}$ & $\begin{array}{l}\text { (Percentage) } \\
(\%)\end{array}$ \\
\hline \multicolumn{4}{|c|}{ Family Relationship } \\
\hline \multicolumn{4}{|c|}{ 1. Satisfied sexual relation } \\
\hline Yes & & 67 & 55.8 \\
\hline No & & 53 & 44.2 \\
\hline Total & & 120 & 100 \\
\hline \multicolumn{4}{|c|}{ 2. Financial problems } \\
\hline Yes & & 63 & 52.5 \\
\hline No & & 57 & 47.5 \\
\hline Total & & 120 & 100 \\
\hline \multicolumn{4}{|c|}{ 3. Communication problems } \\
\hline Yes & & 61 & 50.8 \\
\hline No & & 59 & 49.2 \\
\hline Total & & 120 & 100 \\
\hline \multicolumn{4}{|c|}{ Suicide } \\
\hline Yes & & 25 & 20.8 \\
\hline No & & 95 & 79.2 \\
\hline Total & & 120 & 100 \\
\hline \multicolumn{4}{|c|}{ Addiction } \\
\hline Yes & & 33 & 27.5 \\
\hline No & & 87 & 72.5 \\
\hline Total & & 120 & 100 \\
\hline
\end{tabular}

Table (4) revealed that the highest mean score was for the variable perceived social support followed by the variable stressful life events and at last the variable medication building adherence as (Mean=47.99, Mean=19.817andMean=13.641) respectively.

Table (4):Mean scores ,standard deviation of medication adherence, stressful life events and perceived social support of the studied subjects $(\mathrm{N}=120)$

\begin{tabular}{|l|l|l|}
\hline \multicolumn{1}{|c|}{ Variables } & \multicolumn{1}{|c|}{ Mean } & Std. Deviation \\
\hline Medication adherence (total) & 13.641 & 2.028 \\
\hline Stressful life events (total) & 19.817 & 2.238 \\
\hline Perceived social support (total) & 47.992 & 12.788 \\
\hline
\end{tabular}


Table (5) represented that, there was highly statistical significant correlations between hospital stay and patients' age,marital status and occupation as $(\mathrm{r}=.465 ; \mathrm{p}=.000),(\mathrm{r}=.217 ; \mathrm{p}=.017)$ and $(\mathrm{r}=.286 ; \mathrm{p}=.002)$ respectively. A correlation was found between number of hospitalization and level of education but not proved to be statistically significant as $(\mathrm{r}=.174 ; \mathrm{p}=.057)$.

Table (5): Relationship between socio-demographic variables of the studied subjects and their medical profile $(\mathrm{N}=120)$

\begin{tabular}{|l|l|l|l|l|l|l|}
\hline \multirow{2}{*}{ Variables } & Diagnosis & \multicolumn{7}{|l|}{ Number of hospitalization } & \multicolumn{2}{l|}{ Hospital stay } \\
\cline { 2 - 7 } & $\mathbf{r}$ & $\mathbf{p}$ & $\mathbf{r}$ & $\mathbf{p}$ & $\mathbf{r}$ & $\mathbf{p}$ \\
\hline Gender & .123 & .181 & .109 & .237 & .068 & .463 \\
\hline Age & .086 & .348 & .333 & $.000^{*}$ & .465 & $.000^{*}$ \\
\hline Marital status & .112 & .223 & .073 & .428 & .217 & $.017^{*}$ \\
\hline Level of education & .083 & .367 & .174 & .057 & .162 & .077 \\
\hline Occupation & .055 & .547 & .150 & .101 & .286 & $.002^{*}$ \\
\hline
\end{tabular}

Table (6) clarified that there was statistical significant correlation between medication adherence and patients' gender as $(r=.284 ; \mathrm{p}=.002)$. Results also showed that, there was highly statistical significant correlations between stressful life events and patients' age and level of education where $(r=.440 ; p=.000)$ and $(\mathrm{r}=.311 ; \mathrm{p}=.001)$ respectively. There was highly statistical significant correlations between social support and patients' gender, age and occupation as $(\mathrm{r}=.348 ; \mathrm{p}=.000),(\mathrm{r}=.328 ; \mathrm{p}=.000)$ and $(\mathrm{r}=.212 ; \mathrm{p}=.020)$ respectively.

Table (6): Relationship between medication adherence, stressful life events, social support and sociodemographic variables $(\mathrm{N}=120)$

\begin{tabular}{|l|l|l|l|l|l|l|}
\hline \multirow{2}{*}{ Variables } & \multicolumn{2}{|l|}{ Medication adherence } & \multicolumn{2}{l|}{ Stressful life events } & \multicolumn{2}{l|}{ Social support } \\
\cline { 2 - 7 } & $\mathbf{r}$ & $\mathbf{p}$ & $\mathbf{r}$ & $\mathbf{p}$ & $\mathbf{r}$ & $\mathbf{p}$ \\
\hline Gender & .284 & $.002^{*}$ & .026 & .775 & .348 & $.000^{*}$ \\
\hline Age & .060 & .518 & .440 & $.000^{*}$ & .328 & $.000^{*}$ \\
\hline Marital status & .166 & .070 & .075 & 0416 & .057 & .535 \\
\hline Level of education & .024 & .798 & .311 & $.001^{*}$ & .019 & .839 \\
\hline Occupation & .089 & .336 & .042 & .647 & .212 & $.020^{*}$ \\
\hline
\end{tabular}

Table (7) revealed that statistical significant correlation was found between number of hospitalization and social support at $(\mathrm{r}=.231 ; \mathrm{p}=.011)$.Also, statistical significant correlation was found between length of hospital stay and medication adherence at $(\mathrm{r}=.225 ; \mathrm{p}=.013)$.

Table (7): Relationship between number of hospitalization, hospital stay and medication adherence, stressful life events, social support $(\mathrm{N}=120)$

\begin{tabular}{|l|l|l|l|l|l|l|}
\hline \multirow{2}{*}{ Variables } & \multicolumn{2}{l|}{ Medication adherence } & \multicolumn{2}{l|}{ Stressful life events } & \multicolumn{2}{l|}{ Social support } \\
\cline { 2 - 7 } & $\mathbf{r}$ & $\mathbf{p}$ & $\mathbf{r}$ & $\mathbf{p}$ & $\mathbf{\text { r }}$ & p \\
\hline Number of hospitalization & .153 & .096 & .108 & .239 & .231 & $.011^{*}$ \\
\hline Hospital Stay & .225 & $.013^{*}$ & .021 & .822 & .655 & .041 \\
\hline
\end{tabular}

Table (8) showed that statistical significant correlations were found between medication adherence and financial problems at $(\mathrm{r}=.195 ; \mathrm{p}=.009)$ and communication problems at $(\mathrm{r}=.201 ; \mathrm{p}=.027)$. Also statistical significant correlations were found between stressful life events and sexual relationship at $(r=.236 ; p=.010)$ and financial problems at $(\mathrm{r}=.086 ; \mathrm{p}=.348)$.Statistical significant correlations was found between social support and sexual relation at $(\mathrm{r}=.275 ; \mathrm{p}=.002)$.

Table(8):Relationship between family relationship and medication adherence, stressful life events, social support $(\mathrm{N}=120)$

\begin{tabular}{|c|c|c|c|c|c|c|}
\hline \multirow[t]{2}{*}{ Family Relationship } & \multicolumn{2}{|c|}{ Medication adherence } & \multicolumn{2}{|c|}{ Stressful life events } & \multicolumn{2}{|c|}{ Social support } \\
\hline & $\mathbf{r}$ & $\mathbf{p}$ & $\mathbf{r}$ & $\mathbf{p}$ & $\mathbf{r}$ & p \\
\hline Satisfied sexual relation & .100 & .279 & .236 & $.010^{*}$ & .275 & $.002 *$ \\
\hline Financial problems & .195 & $.009 *$ & .086 & .348 & .029 & .749 \\
\hline Communication problems & .201 & $.027 *$ & .178 & .052 & .095 & .303 \\
\hline
\end{tabular}

\section{Discussion}

The previous researches have demonstrated that readmission is commonly used as an outcome or quality indicator for psychiatric inpatient services. Hospital readmission, particularly when it occurs within relatively short time after previous discharge, is often seen as a failure of the earlier hospital admission $[21,22 \&$ 12]. 
Several factors were identified to be associated with psychiatric readmission. The relationship between socio-economic status and admissions to hospital for mental illness has been recognized [23]. These findings revealed that, more than half of the studied subjects were readmitted to psychiatric hospitals more than one time $64.1 \%$ this is inconsistent with a study done by[23] showed that $32.18 \%$ of the patients were readmitted within six months after discharged. The only associated factor with early readmission was poor compliance to medications, which was defined as missed medication for two weeks or more in the same line, another study by[24] reported that readmissionis responsible for up to half of all hospital admissions. A study by[25] reported that hospital readmission, particularly when it occurs within relatively short time after previous discharge, is often seen as a failure of the earlier hospital admission. On contrary, only a small number of reports have addressed the phenomenon of early readmission despite the fact that it is as high as $30 \%$ of all discharged patients.

In relation to medication adherence, study findings reported that nearly about one third of the study subjects were non adherence to medication this finding was similar to a study done by [26]reported that, nonadherence can range from patients who refuse to take medications due to lack of acceptance of the need for medication, to patients who recognize the need for medication and are committed to treatment but are nonadherent due to forgetfulness or financial constraints. In the same context some researchers proved that the relative risk ratio for consistently poor adherence was (3.81) for African Americans compared to whites and (3.54) for Hispanics compared to whites. Lack of family support for adherence, or having no family, further contributes to non-adherence[24].Furthermore,[27] found thatnon-adherence to medications during the first week after discharge from an inpatient hospitalization was associated with a high risk for re-hospitalization within one month of discharge. Length of hospital stay is also extended due to non-adherence.[28,29 ]found that, an average hospital costs in non-adherent inpatients were three times higher than costs for adherent inpatients, although pharmacy costs were higher among adherent compared to non-adherent inpatients. In that sense, some studies related to success of treatment adherence with different levels of commitment related to the patients' role, their relation with health services-professionals and with the quality of care the professional delivers. All of these involved the need for a good interpersonal relationship, knowledge, understanding and techniques that helped with treatment maintenance.

Thus, it was expected that patients with good knowledge about their disease and treatment can experience significant improvements in terms of adherence, to the extent that they gradually accept and understand their situation, resources and potentials. Although they suggested that health education can also influence patients and families' involvement in health care.

Study findings also reported that the highest total mean scores and SD were found in perceived social support $(47.99,12.7)$ this finding was consistent with $[30,31]$ as they stated that, social support is a particularly important factor in assisting people with schizophrenia to decrease their length of hospital stay and in turn, reintegrate in the community. On contrary, previous studies noted that social support as a basic aspect of human life is often lacking in the lives of people with serious mental illness. Numerous studies found people with mental illness, particularly schizophrenic disorders, to be socially isolated. Their networks are small compared with those of persons without mental illness and relationships are often restricted to the immediate family, with few other social groups to refer to. Hospitalizations[32,33,34] When hospitalization is necessary, both client and network members should be encouraged to remain in contact with each other throughout. The nurse role should include an assessment of a patient's social network and social support on a regularly basis. Building client's network skills through social skills training includes strategies to assist clients in improving communication skills, patterns of eye contact, physical proximity, posture and grooming.

The current study findings also indicated that, a statistically negative relation was found between number of hospitalization and drug adherence, as well as a statistically significant positive relation was found between hospital stay and drug adherence. This result was congruent with [35]who reported in their study that, a strong association between non adherence to treatment and multiple psychiatric readmissions. The most common reason for treatment non-compliance was patient refusing to take medicine and non-affordability of medicine. Majority of readmitted patients were not using depot anti-psychotic medication. Moreover,[23]found that $18 \%$ of the patients were readmitted within six months after discharged. The only associated factor with early readmission was poor compliance to medications, which was defined as missed medication for two weeks or more in the study.

Non-adherence to medication can lead to relapse, which can mean more visits to the emergency room, re-hospitalizations and increased need for clinician intervention all of which lead to increased costs to healthcare systems therefore it is important to identify the key factors contributing to non-adherence in schizophrenia, and their consequences. In addition, assessing causes and consequences of non-adherence together may highlight the importance and complexity of adherence to medication in schizophrenia.

Readmission is high among psychiatric patients. Poor adherence to medication is associated with psychiatric early readmission. If the treatment program seeks to decrease the incidence of early readmission, 
greater attention must be paid to help the patients to recognize their own symptoms and understand their illness with the aim to improve medication adherence. The current study findings also emphasized that, a statistically significant relation was found between medication adherence and financial problems. This result was supported by [25]who highlighted in his study that, typical reasons cited by patients for not taking their medications included forgetfulness $(30 \%)$, medication cost $(22 \%)$, other priorities $(16 \%)$, decision to omit doses $(11 \%)$, lack of information (9\%), and emotional factors $(7 \%)$ moreover, Increase in patient medication cost share was found to be associated with low adherence to medication [36].According to the Kaiser Family Foundation survey in 2015, approximately three quarters $(73 \%)$ of the public think the drug prices are unreasonable and blame pharmaceutical companies for setting prices so high. Furthermore, the finding also reflected number of hospitalization is significantly correlated with social support, this result was supported by [37]who highlighted in their study that, persons admitted frequently to mental hospitals or those with prolonged hospitalization have distinctly smaller networks composed for the first time. Also it will be difficult for individuals to reintegrate into community after hospitalization .In the same context, Another study by [30]further found that, people with a larger network, with high level of support located in family and outside the family, have been rarely hospitalized this is incongruent with a study done by [38]who stated that, patients with repeated hospital admissions have networks composed of more mental health and service professionals. Also social support has been found to be important in keeping mentally ill persons functioning well in the community and in reducing the likelihood of recurrence of mental illness symptoms. On the other hand a study done by [39]found that "duration of hospital stay was not significantly related to the number of supportive persons, although there was a tendency for the duration of hospital stay to be inversely correlated with the number of supportive persons" .Lastly statistical significant relation were found between age, length of stay and number of hospitalization this was congruent with [13] who emphasized that more than one third of the long stay patients were in the age group of "fifty years and more". This result is not surprising as older people have been found to stay longer lengths of hospitalization. Furthermore ,this result matched with[40] who classified age as one of the five variables significantly predicting length of hospital stay steadily overtime.

\section{Conclusion And Recommendation:}

In conclusion, readmission was high among psychiatric patients. Poor adherence to medication was related to psychiatric early readmission. Statistical significant difference was found between number of hospitalizations and social support. Also, statistical significant difference was found between length of hospital stay and medication adherence, as well as statistical significant difference was found between medication adherence and financial problems.

\section{Recommendations}

\section{Based on the findings of the present research the following recommendations were suggested:}

- Implementation of psycho-educational program for patients and their families to reduce risk factors associated with readmission and preventive measures.

- Future studies should be applied to include other variables related to readmission.

- A future study should be planned to focus on early readmissions and to consider the issue of whether or not they could have been prevented.

- Further researches are required on a larger sample on mentally ill patients to generalize the results.

- Policy makers should discover specific methods of aftercare and types of services that can ensure that discharged psychiatric patients remain in the community.

\section{Refrences}

[1]. Arnold, E.M., Goldston, D.B., Ruggiero, A., Reboussin, B. A., Daniel, S. S. and Hickman, E. A. (2003). Rates and predictors of rehospitalization among formerly hospitalized adolescents. Psychiatric Services, vol. 54, no. 7, pp. 994-998.

[2]. Montgomery, P., and Kirkpatrick, H. (2002).Understanding those who seek frequent Psychiatric hospitalizations. Archives of Psychiatric Nursing, Vol. 16, no.1 pp. 15-24.

[3]. Bridg, J.A., Barb, R.P. (2004). Reducing hospital readmission in depression and Schizophrenia: Current evidence. Current Opin Psychiatry; 17:505-11.

[4]. Rosca, P., Bauer, A., Grinshpoon, A., Khawaled, R., Mester, R., and Ponizovsky, A. M. (2006). Re-hospitalizations among psychiatric patients whose first admission was involuntary: A 10-year follow-up. Israel Journal of Psychiatry and Related Sciences, vol. 43, no. 1, pp. 57-64.

[5]. Davies, S., Fallow, S., Bruce, J., et al. (2001). Early outcomes of supervised discharge. Med Sci Law.41 (1):31-4.

[6]. Dilonardo, J. D., Connelly, C.E., Gurel, L., et al. (1998). Scheduled intermittent hospitalization for psychiatric patients.Psychiatr Serv. 49 (4):504-9.

[7]. Castro, A.P., and Elkis, H. (2007). Re-hospitalization rates of patients with schizophrenia discharged on haloperidol, risperidone or clozapine. Rev Bras Psiquiatr, 29 (3):207-212.

[8]. Magliano, L., Marasco, C., Fiorillo, A., Malangone, C., Guarneri, M., Maj, M. (2002). The impact of professional and social network support on the burden of families of patients with schizophrenia in Italy.ActaPsychiatr Scand.106 (4): 2918 
[9]. Magliano, L., Fiorillo, A., Malangone, C., De RC., and Maj, M. (2006). Social network in long-term diseases: a comparative study in relatives of persons with schizophrenia and physical illnesses versus a sample from the general population. SocSci Med; 62 (6): $1392-402$

[10]. Botha, U.A., Koen, L., Galal, U., et al. (2014). The rise of assertive community interventions in South Africa: A randomized control trial assessing the impact of a modified assertive intervention on readmission rates; a three year follow-up. BMC Psychiatry, 14 (1).

[11]. Sheitman, B.B., Lee, H., Strauss, R., and Lieberman, J.A. (1997).The evaluation and treatment of first episode psychosis.Schizphr Bull. 23: 653-661.

[12]. Craig T. J., Fennig, S., Tanenberg- Karant, M., and Bronet, E. J. (2009). Rapid versus delayed readmission in first admission psychosis: Quality indicators for managed care? Ann Clin Psychiatry. 12: 233-238.

[13]. Bobier, C., and Warwick, M. (2005). Factors associated with readmission to adolescent psychiatric care. Aust NZ J Psychiatry. 39 (7):600-606. doi: 10.1111/j.1440-1614.2005.01632.

[14]. Häfner, H., and Van der Heiden, W. (1989). The evaluation of mental health care systems. Br. J. Psychiatry.155:12-7.

[15]. Olfson, M., Mechanic, D., Hansell, S., Boyer, C.A., Walkup, J., and Weiden, P.J. (2012). Predicting medication noncompliance after hospital discharge among patients with schizophrenia.Psychiatr Serv. 51(2):216-22.

[16]. Voruganti, L., Baker, L., and Awad, A.G. (2008). New generation antipsychotic drugsand compliance behavior.CurrOpinPsychiatr. 21(2): 133-9.

American Psychiatric Nursing Association (2012). stress in America paying with our health. Available at https//www. Apa .org/news/press/stress-report.

[18]. Thompson, K., Kulkarni, J., and Sergejew, A.A. (2000). Reliability andvalidity of a new Medication Adherence Rating Scale (MARS) for the psychoses.SchizophreniaResearch. Volume 42, Issue 3, 5 May 2000, Pages 241-247.

[19]. Brugha TS, Cragg D. The list of threatening experiences: The reliability and validity of a brief Life Events Questionnaire. Act Psychiatr Scand. 1990; 82:77-81.

[20]. Zimet, G.D., Dahlem, N.W., Zimet, S.G. and Farley, G.K. (1988). The Multidimensional Scaleof Perceived Social Support. Journal of Personality Assessment, 52, 30-41.

[21]. Jenkins, R. (1991). Toward a system of outcome indicators for mental health care. Jenkins R, Griffiths (eds) Indicators for mental health in the population. Department of Health, London.

[22]. Lyons, J.S., O’Mahoney, M.T., Miller, S.I., Neme, J., Kabat, J., Miller, F. (1997). Predicting readmission to the psychiatric hospital in a managed care environment: Implications for quality indicators. Am J Psychiatry.154 : 337-340.

[23]. Ng, C.G., Loh, H.S., Yee, H.A, Zainal, N.Z. (2012). The prevalence and associated factors of psychiatric early readmission in a teaching Hospital, original paper, MJP Online Early.

[24]. Valenstein, M., Gaznoczy, D., McCarthy, J.F., Myra Kim, H, Lee, T.A, Blow, F.C. (2006). Antipsychotic adherence over time among patients receiving treatment for schizophrenia: A retrospective review. J Clin Psychiatry; 67(10): 1542-1550.

[25]. Alene, M., Wiese, M. D., Angamo, M. T., Bajorek, B. V., Yesuf, E. A., and Wabe, N. T. (2012). Adherence to medication for the treatment of psychosis: Rates and risk factors in an Ethiopian population. BMC Clinical Pharmacology, vol. 12, article 10.

[26]. Velligan, D.I., Lam, Y.W., Glahn, D.C, et al. (2006). Defining and assessing adherence to oral antipsychotics: A review of the literature. Schizophr Bull.; 32(4):724-742.

[27]. Bodén R., Brandt, L., Kieler, H., Andersen M, Reutfors J. (2011). Early non-adherence to medication and other risk factors for rehospitalization in schizophrenia and schizoaffective disorder.Schizophr Bull.; 133(1-3):36-41.

[28]. Zipursky, R.B., Menezes, N.M., Streiner, D.L. (2014). Risk of symptom recurrence with medication discontinuation in first-episode psychosis: a systematic review. Schizophr Res.; 152(2-3):408-414

[29]. Gilmer, T.P., Dolder, C.R., Lacro, J.P., et al. (2004). Adherence to treatment with antipsychotic medication and health care costs among medicaid 052beneficiaries with schizophrenia. Am J Psychiatry. 161(4):692-699.

[30]. Cechnickim, A. and Wojciechowska, A. (2007). Correlations between features of social network and outcomes in those suffering from schizophrenia seven years from the first hospitalization. Psychiatric Policy, 41: 513-525

[31]. Hiroaki, M., Hisateru, T. and Tadashi, (2008). Providing support to psychiatric patients living in the community in Japan: Patient needs and care providers' perceptions. International Journal of Mental Health Systems, 10: 1752-1771.

[32]. Chinuman, M.J., Eingarten, R., Stayner, D., and Davidson, L. (2001). Chronicity reconsidered: improving person-environment through a consumerrun service. Community Mental Health Journal, 37: 215-29.

[33]. Muller, B., Nordt, C., Lauber, C., and Rossler, W. (2007). Changes in social network diversity and perceived social support after psychiatric hospitalization: Results from a longitudinal Study. International J. Soc. Psychiatry, 53: 564-575.

[34]. Sawant, N.S., and Jethwani, K.S. (2010). Understanding family functioning and Social Support in unremitting schizophrenia: A study in India. Indian J. Psychiatry, 52: 145-149.

[35]. Prince, J. D., Akincigil,A., Kalay, E. et al. (2008).Psychiatric re-hospitalization among elderly persons in the United States. Psychiatric Services, vol. 59, no. 9, pp. 1038-1045.

[36]. Eaddy, M.T., Cook, C.L., O'Day K., Burch, S.P., Cantrell, C.R. (2012). How patient cost-sharing trends affect adherence and outcomes: A Literature review. Pharmacy and Therapeutics. 37 (1): 45-55.

[37]. McCorkle, B., Tugers, E.S. Dunn, E.C., Layas, A., and Wan, Y.M. (2008). Increasing social support for individuals with serious mental illness: Evaluating the compeer model of intentional friendship. Community Mental Health Journal, DOI 10.1007/s$008=9137-8$.

[38]. Holmes-Eber, P.H. and Stephanie, R. (1990). Hospitalization and composition of mental patients' social networks. Schizophrenia Bulletin, 18: 157-164.

[39]. Ossman, L. H. and Mahmoud,N.M. (2012) Social Support and Length of Hospital Stay among Schizophrenic Patients. World Applied Sciences Journal 19 (5): 625-633, 2012 ISSN 1818-4952; (C) IDOSI Publications, 2012 DOI: 10.5829/idosi.wasj.2012.19.05.6519.

[40]. Jimenez, R.E., Lam, R.M. Marot, M., and Delgado, A. (2004).Observed-predicted length of stay for acute care inefficiencies. Retrospective case-series study. BMC Health Services Research. Available at: http://www.biomedcentral.com/1472-6963/4/4. Retrieved on: 11/7/2010 